\title{
Association between Hospital Imaging Use and Venous Thromboembolism Events Rates Based on Clinical Data
}

\author{
Mila H. Ju, MD, MS ${ }^{1,2}$, Jeanette W. Chung, Ph.D ${ }^{2}$, Christine V. Kinnier, MD², David J. \\ Bentrem, MD, MS ${ }^{2}$, David M. Mahvi, MD², Clifford Y. Ko, MD, MS, MSHS ${ }^{1,3}$, and Karl Y. \\ Bilimoria, MD, MS $^{1,2}$ \\ ${ }^{1}$ Division of Research and Optimal Patient Care, American College of Surgeons, Chicago, IL \\ ${ }^{2}$ Surgical Outcomes and Quality Improvement Center, Department of Surgery, Northwestern \\ University, Chicago, IL \\ ${ }^{3}$ Department of Surgery, University of California, Los Angeles (UCLA) and VA Greater Los \\ Angeles Healthcare System, Los Angeles, CA
}

\begin{abstract}
Objective-The objective was to assess the presence and extent of venous thromboembolism [VTE] surveillance bias using high-quality clinical data.

Summary Background Data-Hospital VTE rates are publicly reported and used in pay-forperformance. Prior work suggested surveillance bias: hospitals that look more for VTE with imaging studies find more VTE, thereby incorrectly appear to have worse performance. However, these results have been questioned as the risk-adjustment and VTE measurement relied on administrative data.
\end{abstract}

Methods-Data (2009-2010) from 208 hospitals were available for analysis. Hospitals were divided into quartiles according to VTE imaging use rates (Medicare claims). Observed and riskadjusted postoperative VTE event rates (regression models using ACS NSQIP data) were examined across VTE imaging use rate quartiles. Multivariable linear regression models were developed to assess the impact of hospital characteristics (American Hospital Association) and hospital imaging use rates on VTE event rates.

Results-The mean risk-adjusted VTE event rates at 30-days after surgery increased across VTE imaging use rate quartiles: $1.13 \%$ in lowest to $1.92 \%$ in highest quartile $(\mathrm{P}<0.001)$. This statistically significant trend remained when examining only the inpatient period. Hospital VTE imaging use rate was the dominant driver of hospital VTE event rates $(\mathrm{P}<0.001)$, as no other hospital characteristics had significant associations.

Conclusions-Even when examined with clinically ascertained outcomes and detailed risk adjustment, VTE rates reflect hospital imaging use and perhaps signify vigilant, high-quality care.

Corresponding Author: Karl Y. Bilimoria, MD MS, Division of Research and Optimal Patient Care, American College of Surgeons, 633 N. St. Clair Street, 22nd Floor, Chicago, IL 60611, Office: 312-695-4853, Fax: 312-695-1462, kbilimoria@ facs.org.

Conflict of Interest Disclosures: No conflict of interest related to this work. 
The VTE outcome measure may not be an accurate quality indicator and should likely not be used in public reporting or pay-for-performance programs.

\section{Introduction}

Venous thromboembolism [VTE], which is comprised of deep vein thrombosis [DVT] and pulmonary embolism [PE], is a potentially life-threatening complication among hospitalized patients, particularly after major surgery. ${ }^{1-4}$ Postoperative VTE affects approximately $1 \%$ of all patients undergoing surgery in the U.S. ${ }^{2,5}$ VTE quality of care measures are included in many hospital quality improvement and public reporting initiatives in an effort to lower postoperative VTE rates. ${ }^{6,7}$ Additionally, VTE is a "never-event" that is not additionally reimbursed by the Centers for Medicare and Medicaid Services [CMS] after certain operations. ${ }^{8}{ }^{8}$ VTE performance will also be tied to financial penalties through the 2015 CMS Value-Based Purchasing initiative.

However, the validity of the VTE measure has been questioned. ${ }^{10,11}$ Several studies have suggested a so-called surveillance bias or "the more you look, the more you find" phenomenon. ${ }^{11-15}$ Hospitals that are vigilant, look more frequently for VTE, and find more VTE are then inadvertently penalized for having high VTE rates. However, the only comprehensive study examining this issue used Medicare administrative claims data limited to patients 65 years and older. ${ }^{10}$ Compared to data from clinical registries, administrative data are not as accurate for ascertaining true VTE events compared to data from clinical registries, as administrative data have been shown to have high false-positive and falsenegative rates. ${ }^{16-18}$ Moreover, administrative data are limited in the preoperative risk factors and comorbidities available for detailed risk adjustment. The administrative data are generally also limited to the inpatient period only, but the post-discharge period is important given the relatively high proportion of events that occur outside the hospitals, especially with increasingly shorter lengths of stay. ${ }^{19}$

To address these limitations of our prior study of surveillance bias and VTE, we used highquality clinical data including a wide range of age groups and operative procedures from the American College of Surgeons National Surgical Quality Improvement Project [ACS NSQIP].${ }^{20} \mathrm{ACS}$ NSQIP data has been shown to be more accurate than administrative data, given its rigorous data collection system using standardized definitions and thorough validation process through formal audits. ${ }^{17}$ ACS NSQIP data also captures both inpatient and post-discharge events to 30 days after index surgery, and contains more than 30 variables for comprehensive risk adjustment. Therefore, the objectives of this study were (1) to examine whether a surveillance bias is associated with measured VTE event rates using robust clinical data; and (2) to assess whether VTE imaging use rates or other hospital characteristics are associated with VTE event rates. We hypothesized that hospitals with higher VTE imaging use rates would have higher VTE events rates when using accurate, standardized, audited, and validated clinical data from ACS NSQIP. By using Medicare data to assess hospital VTE imaging use and ACS NSQIP data to ascertain VTE events and perform risk adjustment, this study offers the only way available currently to examine this issue using clinical data from a large sample of hospitals. 


\section{Methods}

\section{Hospital VTE Event Rates}

To overcome limitations of previous studies, the 2009 to 2010 ACS NSQIP database was used to determine hospital VTE event rates. ACS NSQIP is a national multi-specialty surgical registry with data that are rigorously collected by trained surgical clinical reviewers using standardized data definitions and validated through a formal audit process. ${ }^{21}$ Outcomes are ascertained by the data abstractors in a standardized fashion at 30 days after the index surgery irrespective of whether the patient is inpatient, discharged, or admitted at another institution.

Patients 18 years or older who underwent 11 major surgical procedures (abdominal aortic aneurysm repair, bariatric surgery, brain tumor resection, colon resection, coronary artery bypass graft [CABG], cystectomy, esophagectomy, lung resection, pancreatectomy, rectal surgery, and total knee arthroplasty) were identified using the American Medical Association Current Procedural Terminology [CPT] codes (Supplemental Table 1). The procedures were selected as they have policy relevance or are frequently examined in surgical quality evaluations.

When coded by the data abstractors, the ACS NSQIP definition of DVT and PE requires image confirmation and treatment of the blood clot. Hospital risk-adjusted VTE event rates were calculated using the standard ACS NSQIP modeling approach which has been previously well described and accounts for differences in patient comorbidities. ${ }^{22}$ More than 30 patient characteristics were available for risk adjustment in multivariable logistic regression models including age, sex, race, American Society of Anesthesiologists physical status classification, functional status, comorbidities, and abnormal preoperative laboratory values. Risk adjusted VTE, DVT, and PE rates were calculated for events occurring within 30 days after the index operation and also for events that occurred only during the index inpatient postoperative stay.

\section{Hospital VTE Imaging Use Rates}

Data on hospital VTE imaging studies were obtained from the Medicare Provider and Analysis Review, Carrier, and Outpatient claims files from January 1, 2009 to December 31, 2010. This currently represents the only way to obtain detailed data on VTE imaging use rates for most hospitals in the U.S. Using International Classification of Diseases, Ninth Revision [ICD-9] codes (Supplemental Table 1), patients over 65 years of age who underwent the same 11 major surgical procedures noted above were identified.

VTE imaging studies (venous duplex ultrasonography of upper or lower extremity for DVT; chest computed tomography scans, chest magnetic resonance imaging, ventilation-perfusion scans, and venograms for PE) were identified using the CMS Healthcare Common Procedure Coding System [HCPCS] codes (Supplemental Table 3) for postoperative services rendered during the inpatient period. Hospital VTE imaging use rates were defined as the number of surgical (Medicare) discharges that had any VTE-related imaging studies obtained per total number of Medicare surgical discharges. VTE, DVT, and PE were 
examined separately. The hospitals were then divided into 4 quartiles using VTE imaging use rates with approximately equal numbers of hospitals in each quartile.

\section{Hospital Characteristics}

Hospital structural characteristics were identified from the 2010 American Hospital Association [AHA] Annual Survey. ${ }^{23-29}$ These characteristics reflect a hospital's resources and focus on specialized programs designed and intended to provide higher quality care. ${ }^{30}$ Bed size was dichotomized to $<500$ and $\geq 500$ beds. Teaching status was determined by whether the hospital was a member of Council of Teaching Hospitals and Health Systems [COTH] of the Association of American Medical Colleges [AAMC] or had other teaching hospital designation (i.e., residency training approval from Accreditation Council for Graduate Medical Education [ACGME], medical school affiliation with American Medical Association [AMA] or American Osteopathic Association [AOA]). ${ }^{31}$ Structural quality characteristics included Joint Commission [JCAHO] accreditation; presence of a cancer program approved by the ACS Commission on Cancer [CoC]; certification as a Level I Trauma Center; provision of burn care services; and provision of transplant surgery services. In addition, the number of individual structural quality characteristics for each hospital were summed ( 5 total) to evaluate how an increasing number of characteristics would affect performance on risk-adjusted VTE, DVT, and PE event rates.

\section{Statistical Analysis}

Data regarding hospital VTE imaging use rates, VTE event rates, and structural characteristics were merged for each hospital. Only hospitals with data for both VTE imaging use rates and VTE event rates were included in the analysis. Hospitals were grouped into quartiles based on VTE imaging use rates.

The relationship between hospital DVT and PE imaging rates was assessed with bivariate Spearman correlations. Hospital observed and risk-adjusted VTE event rates during the inpatient only and at 30-day postoperative periods were examined by quartile of VTE imaging use rate. The Cuzick extension of Wilcoxon rank-sum test was used to test for significant trends across quartiles. One-way analysis of variance with Bonferroni corrections for multiple pairwise comparisons was used to test for differences in mean rates of VTE events across VTE imaging use rate quartiles. Sensitivity analyses were performed for DVT and PE only events and imaging use.

The association between hospital risk-adjusted VTE, DVT, and PE event rates and hospital characteristics (bed size, teaching status, number of structure quality characteristics, and hospital VTE imaging use rate) was examined using multivariable linear regression. VTE, DVT, and PE were examined separately.

Since the imaging data came from Medicare claims, and Medicare patients are mostly 65 years or older, we repeated the above analyses but restricted ACS NSQIP population to those patients over 64 years old as a sensitivity check. All analyses were performed using SAS statistical software (Release 9.3, SAS Institute Inc., Cary, NC). The level of statistical significance was set at the 0.05 level. The study was reviewed by the Northwestern University Institutional Review Board. 


\section{Results}

\section{Hospital VTE Event Rates}

From the 208 hospitals that had data for both VTE imaging use rates and VTE event rates, 131,512 patients from the ACS NSQIP database were used to calculate the hospital riskadjusted VTE event rates. The majority of these patients were less than 65 year sold (63.4\%), white (77.4\%), independent functional status (93.6\%), and ASA class II or III $(89.0 \%)$ (Table 1). The overall 30-day VTE rate in the study cohort was $1.6 \%$ (DVT rate $1.1 \%$, PE rate $0.6 \%$ ). When limited to the inpatient only period, the VTE rate was $1.0 \%$ (DVT rate $0.8 \%$, PE rate $0.3 \%$ ).

\section{Hospital VTE Imaging Use Rates}

Hospitals had a mean of 5.27 (standard deviation [SD] 1.54) VTE imaging studies per 100 cases in quartile 1, 8.19 (SD 0.76) in quartile 2, 10.99 (SD 0.82) in quartile 3, and 15.94 (SD $3.23)$ in quartile $4(\mathrm{P}<0.001$, Table 2$)$. Hospital DVT imaging rates were significantly correlated with hospital PE imaging rates (Spearman's rho 52.1\%, P<0.001; Fig. 1).

\section{Hospital Characteristics}

Out of the 208 hospitals, 94 (45.2\%) had more than 500 beds, 107 (51.4\%) were COTH members, and 161 (78.2\%) had residency programs approved by ACGME (Table 3). The majority of these hospitals were accredited by the Joint Commission $(189 ; 91.8 \%)$ or had a cancer program accredited by the $\mathrm{CoC}(170 ; 82.5 \%)$, but only a minority provided burn services $(44 ; 21.4 \%)$.

\section{Evaluation of Surveillance Bias}

For VTE events captured at 30-days, the mean risk-adjusted VTE event rate for hospitals in VTE imaging use rate quartile 1 was $1.13 \%$ (SD 0.70), quartile 2 was $1.46 \%$ (SD 0.77), quartile 3 was $1.49 \%$ (SD 0.75), and quartile 4 was $1.92 \%$ (SD 1.45) ( $\mathrm{P}=0.001$ trend and $\mathrm{P}<0.05$ pairwise compared to $4^{\text {th }}$ quartile; Table 2). For VTE events captured during the inpatient period only, the mean hospital risk-adjusted VTE event rate for hospitals in quartile 1 was $0.67 \%$ (SD 0.52), quartile 2 was $0.99 \%$ (SD 0.95), quartile 3 was $1.02 \%$ (SD 0.2 ), and quartile 4 was $1.33 \%$ (SD 1.53) $(\mathrm{P}=0.002$ trend and $\mathrm{P}<0.050$ pairwise compared to $4^{\text {th }}$ quartile; Figure 2). The same trends were found when examining DVT and PE events separately. The mean hospital risk-adjusted DVT event rates increased from $0.48 \%$ (SD 0.46 ) in quartile 1 to $1.00 \%$ (SD $0.66 \%$ ) in quartile 4 for DVT events captured during inpatient period only, and from $0.81 \%$ (SD 0.64 ) in quartile 1 to $1.35 \%$ (SD 0.76 ) in quartile 4 for DVT events captured at 30-days. The mean hospital risk-adjusted PE event rates increased from $0.21 \%$ (SD 0.23) in quartile 1 to $0.45 \%$ (SD 0.53) in quartile 4 for PE events captured during inpatient period only, and from $0.41 \%$ (SD 0.35) in quartile 1 to $0.70 \%$ (SD 0.62 ) in quartile 4 for PE events captured at 30-days (Supplemental table 3).

When examining the influence of hospital VTE imaging use rate in comparison with other hospital characteristics (e.g., bed size, teaching status, and number of other structural quality characteristics) on risk-adjusted VTE event rates at 30 days after the surgery, only the $4^{\text {th }}$ quartile of VTE imaging use rate was significantly associated with risk-adjusted VTE event 
rates $(\mathrm{P}<0.001)$, while the $2^{\text {nd }}$ and $3^{\text {rd }}$ quartiles had non-significant trends for the association with risk-adjusted VTE event rates $(\mathrm{P}=0.055$ and $\mathrm{P}=0.053$ respectively). For the inpatient only period, $3^{\text {rd }}$ and $4^{\text {th }}$ quartiles of VTE imaging use rate were significantly associated with risk-adjusted VTE events ( $\mathrm{P}=0.046$ and $\mathrm{P}=0.001$ respectively). None of the other hospital characteristics had a significant association with risk-adjusted VTE event rates (Table 4). Similar findings were seen when examining DVT and PE events separately (Supplemental table 4).

Results from sensitivity analyses restricting the ACS NSQIP population to patients 65 years or older were similar to above findings.

\section{Discussion}

VTE remains one of the leading causes of morbidity and mortality for hospitalized patients, ${ }^{1-3}$ and VTE has been used in several public reporting and value-based purchasing initiatives. ${ }^{8}$ However, using VTE event rates to judge a hospital's quality and ability to prevent VTE may be flawed. In our study using rigorously collected and validated clinical data for VTE event ascertainment and risk adjustment, we found that hospitals that perform more VTE imaging studies (e.g., VTE imaging use rate quartile 4) had higher rates of observed and risk-adjusted VTE event rates than those hospitals that perform fewer studies (quartile 1). These trends were statistically significant for VTE events captured at 30-days and during the inpatient period. Moreover, hospitals that had higher rates of DVT imaging studies also had higher rates of PE imaging studies. VTE imaging rate was the most important predictor of hospital VTE event rate.

We were able to support the findings from previous studies that the presence of surveillance bias exists for the VTE outcome measure. In several studies focused on trauma patients, using data from single institution and the National Trauma Data Bank, trauma centers that performed more venous duplex studies had higher rate of DVT events, ${ }^{12,14,15}$ but this was mostly due to routine venous duplex screening practices in asymptomatic trauma patients. ${ }^{13}$ In our study, we were able to broaden the study cohort to extend beyond the trauma patients to populations where routine screening is generally not performed. We included 131,512 patients with various physical status and comorbidities who underwent 11 types of operations among 208 NSQIP hospitals nationwide. We continue to observe that hospitals that were frequent users of VTE imaging studies had higher rates of observed and riskadjusted VTE events.

In a recent study of nearly one million Medicare beneficiaries from more than 2,800 hospitals, we demonstrated a surveillance bias in the measurement of VTE event rates. ${ }^{10}$ However, the study has been criticized because we used administrative billing data for VTE event ascertainment (i.e., less accurate than clinical data), ${ }^{17,18}$ risk adjustment of VTE event rates using PSI-12 methodology (i.e., potentially inaccurate coding and insufficient risk adjustment), ${ }^{32-34}$ and restriction to only inpatient data and patients over 65 years of age. By using more robust clinically abstracted data from ACS NSQIP, we had more accurate ascertainment of VTE events and were able to better adjust for patient risk factors. Some might argue that certain hospitals have higher risk patients and therefore have higher VTE 
event rates. We were able to better account for this by using the standard ACS NSQIP risk adjustment using more than 30 variables. ${ }^{22}$ Moreover, since ACS NSQIP collects 30-day data, we were also able to extend our study beyond the inpatient period and capture VTE events post-discharge. The results of the present study are not only consistent with the previous study which found that hospitals that were frequent users of VTE imaging studies had higher rates of inpatient VTE, but in addition, our current study finds that the rate of 30day VTE are also associated with hospital volume of VTE imaging.

In addition, we sought to assess hospital characteristics associated with VTE event rates. Prior studies have offered conflicting findings regarding the effect of hospital volume. While Altom et al found that VA hospital surgical volume accounted for $<1 \%$ of the variation in hospital VTE rates, Vartak et al demonstrated that larger hospitals had higher VTE rates. ${ }^{35,36}$ Other studies had shown that VTE rates were higher at teaching hospitals. ${ }^{36,37}$ In our study, we examined a large number of private hospitals of different sizes and teaching status. We found that these hospital factors along with structure quality characteristics such as Joint Commission or CoC accreditations, Level I Trauma Center certification, and burn or transplant services, were not significant in predicting hospital event rates when we had taken into account hospital VTE imaging use rates. In other words, no matter the hospital characteristics, only VTE imaging use rate was significant in predicting hospital VTE event rate. Moreover, hospitals that were frequent users of DVT imaging study were also frequent users of PE imaging studies.

This study should be interpreted considering some limitations. First, there may be a sampling bias since we only examined ACS NSQIP hospitals. However, this allowed us to examine the VTE surveillance bias issue using robust clinical data and overcome the limitation of previous studies. Second, inpatient VTE imaging use rates from our study were limited to Medicare patients, but VTE event rates were calculated from all patients in ACS NSQIP undergoing the same 11 procedures regardless of age or insurance status. Nevertheless, we would expect that hospitals order VTE imaging studies similarly regardless of insurance status, and therefore hospitals would remain in the same VTE imaging use rate quartiles if non-Medicare patients could be included. In addition, we had conducted sensitivity analyses by restricting ACS NSQIP population to patients 65 years or older and found similar results. Third, there may be differences in the procedure mix in the Medicare subpopulation and ACS NSQIP subpopulation within hospitals. The implication is that Medicare surgical populations may have different proportions of procedures that may entail higher VTE risk or VTE imaging utilization in which case the aggregate Medicare imaging utilization rate may be an inaccurate proxy for surveillance in other populations. Unfortunately, we are unable to assess and/or adjust for potential differences in procedure mix across Medicare and NSQIP subpopulations within a hospital given that the exact sampling schedule for each NSQIP hospital is unknown in the available data. However, this was the only way to conduct this study given available national data: Medicare claims data currently represent the only way to obtain detailed data on VTE imaging use rates for most hospitals in the U.S., and the ACS NSQIP data offer the best and largest sample of clinical data for accurate VTE ascertainment and risk adjustment. Fourth, there may be other confounding patient or hospital characteristics that were not accounted for in the VTE event 
rate risk adjustment. These unmeasured confounders could further diminish the VTE event rate differences among the quartiles of VTE image use rate, but using the clinical ACS NSQIP data gives us the best risk adjustment currently possible. In addition, there might be hospitals that provide lower value care at either spectrum of VTE imaging use. Some low imaging use hospitals might be under-detecting VTE because they did not image for VTE, while some high imaging use hospitals might be over-treating patients with clinicallyinsignificant VTE that would otherwise not be found and are inconsequential. Both scenarios are potentially associated with higher morbidity, mortality, and cost. It is possible that due to the discovery of inconsequential VTE, hospitals with lower rates of VTE imaging (and detection) have no less VTE-related morbidity and mortality, and also have lower costs of care, thus potentially providing higher value care. We were unable to discern clinically relevant from irrelevant clots using our data sources. Further research is needed to better understand these issues. Lastly, there may be many other hospital accreditations or quality initiatives that reflect a hospital's commitment to providing higher quality, specialized care. We a priori selected a subset of established hospital characteristics to examine this phenomenon of VTE imaging use rates related to VTE event rates.

\section{Conclusion}

By using clinical data to examine accurate VTE outcomes and detailed patient-level risk adjustments, we were able to verify the findings and address criticisms of previous studies. We found that a surveillance bias affects VTE measurement. Hospitals may be unfairly deemed a poor performer for the outcome VTE measure if they have increased vigilance for VTE by performing more VTE imaging studies which result in higher VTE event rates. VTE rates may not accurately reflect a hospital's ability to prevent VTE. Further research on incorporation of appropriate VTE prophylaxis and image use in addition to VTE rates is necessary to improve the current VTE performance measures.

\section{Supplementary Material}

Refer to Web version on PubMed Central for supplementary material.

\section{Acknowledgments}

Dr. Bilimoria is partially supported by AHRQ R21HS021857. Dr. Ju is supported by National Institutes of Health \#5T32HL094293 and American College of Surgeons Clinical Scholar in Residence program.

\section{References}

1. Beckman MG, Hooper WC, Critchley SE, et al. Venous thromboembolism: a public health concern. Am J Prev Med. 2010; 38:S495-501. [PubMed: 20331949]

2. Geerts WH, Bergqvist D, Pineo GF, et al. Prevention of venous thromboembolism: American College of Chest Physicians Evidence-Based Clinical Practice Guidelines (8th Edition). Chest. 2008; 133:381S-453S. [PubMed: 18574271]

3. Kakkar AK, Cohen AT, Tapson VF, et al. Venous thromboembolism risk and prophylaxis in the acute care hospital setting (ENDORSE survey): findings in surgical patients. Ann Surg. 2010; 251:330-338. [PubMed: 20054273] 
4. Spyropoulos AC, Hussein M, Lin J, et al. Rates of symptomatic venous thromboembolism in US surgical patients: a retrospective administrative database study. J Thromb Thrombolysis. 2009; 28:458-464. [PubMed: 19479199]

5. Zhan C, Miller MR. Excess length of stay, charges, and mortality attributable to medical injuries during hospitalization. JAMA. 2003; 290:1868-1874. [PubMed: 14532315]

6. Amin AN, Deitelzweig SB. Optimizing the prevention of venous thromboembolism: recent quality initiatives and strategies to drive improvement. Jt Comm J Qual Patient Saf. 2009; 35:558-564. [PubMed: 19947332]

7. Merli G. Improving venous thromboembolism performance: a comprehensive guide for physicians and hospitalists. Hosp Pract (Minneap). 2010; 38:7-16.

8. Centers for Medicare \& Medicaid Services (CMS). [Accessed February 27, 2013] Final RuleInpatient Prospective Payment System with Hospital Value-based Purchasing Program Provisions for FY 13, 14, 16. at http://www.gpo.gov/fdsys/pkg/FR-2012-08-31/pdf/2012-19079.pdf

9. Streiff MB, Haut ER. The CMS ruling on venous thromboembolism after total knee or hip arthroplasty: weighing risks and benefits. JAMA. 2009; 301:1063-1065. [PubMed: 19278950]

10. Bilimoria KY, Chung J, Ju MH, et al. Evaluation of Surveillance Bias and the Validity of the Venous Thromboembolism Quality Measure. JAMA. 2013; 310:1482-1489. [PubMed: 24100354]

11. Haut ER, Pronovost PJ. Surveillance bias in outcomes reporting. JAMA. 2011; 305:2462-2463. [PubMed: 21673300]

12. Haut ER, Chang DC, Pierce CA, et al. Predictors of posttraumatic deep vein thrombosis (DVT): hospital practice versus patient factors-an analysis of the National Trauma Data Bank (NTDB). J Trauma. 2009; 66:994-999. discussion 999-1001. [PubMed: 19359905]

13. Haut ER, Schneider EB, Patel A, et al. Duplex ultrasound screening for deep vein thrombosis in asymptomatic trauma patients: a survey of individual trauma surgeon opinions and current trauma center practices. J Trauma. 2011; 70:27-33. discussion 34. [PubMed: 21217477]

14. Haut ER, Noll K, Efron DT, et al. Can increased incidence of deep vein thrombosis (DVT) be used as a marker of quality of care in the absence of standardized screening? The potential effect of surveillance bias on reported DVT rates after trauma. J Trauma. 2007; 63:1132-1135. discussion 1135-1137. [PubMed: 17993962]

15. Pierce CA, Haut ER, Kardooni S, et al. Surveillance bias and deep vein thrombosis in the national trauma data bank: the more we look, the more we find. J Trauma. 2008; 64:932-936. discussion 936-937. [PubMed: 18404058]

16. Davenport DL, Holsapple CW, Conigliaro J. Assessing surgical quality using administrative and clinical data sets: a direct comparison of the University HealthSystem Consortium Clinical Database and the National Surgical Quality Improvement Program data set. Am J Med Qual. 2009; 24:395-402. [PubMed: 19584374]

17. Lawson EH, Louie R, Zingmond DS, et al. A comparison of clinical registry versus administrative claims data for reporting of 30-day surgical complications. Ann Surg. 2012; 256:973-981. [PubMed: 23095667]

18. Best WR, Khuri SF, Phelan M, et al. Identifying patient preoperative risk factors and postoperative adverse events in administrative databases: results from the Department of Veterans Affairs National Surgical Quality Improvement Program. J Am Coll Surg. 2002; 194:257-266. [PubMed: $11893128]$

19. Merkow RP, Bilimoria KY, McCarter MD, et al. Post-discharge venous thromboembolism after cancer surgery: extending the case for extended prophylaxis. Ann Surg. 2011; 254:131-137. [PubMed: 21527843]

20. Shiloach M, Frencher SK Jr, Steeger JE, et al. Toward robust information: data quality and interrater reliability in the American College of Surgeons National Surgical Quality Improvement Program. J Am Coll Surg. 2010; 210:6-16. [PubMed: 20123325]

21. Hall BL, Hamilton BH, Richards K, et al. Does surgical quality improve in the American College of Surgeons National Surgical Quality Improvement Program: an evaluation of all participating hospitals. Ann Surg. 2009; 250:363-376. [PubMed: 19644350] 
22. Cohen ME, Ko CY, Bilimoria KY, et al. Optimizing ACS NSQIP modeling for evaluation of surgical quality and risk: patient risk adjustment, procedure mix adjustment, shrinkage adjustment, and surgical focus. J Am Coll Surg. 2013; 217:336-346. e1. [PubMed: 23628227]

23. American Hospital Association Annual Survey Database. at http://www.ahadataviewer.com/

24. Werner RM, Goldman LE, Dudley RA. Comparison of change in quality of care between safetynet and non-safety-net hospitals. JAMA. 2008; 299:2180-2187. [PubMed: 18477785]

25. Lehrman WG, Elliott MN, Goldstein E, et al. Characteristics of hospitals demonstrating superior performance in patient experience and clinical process measures of care. Med Care Res Rev. 2010; 67:38-55. [PubMed: 19638640]

26. Schmaltz SP, Williams SC, Chassin MR, et al. Hospital performance trends on national quality measures and the association with Ioint Commission accreditation. J Hosp Med. 2011; 6:454-461. [PubMed: 21990175]

27. Brand CA, Barker AL, Morello RT, et al. A review of hospital characteristics associated with improved performance. Int J Qual Health Care. 2012; 24:483-494. [PubMed: 22871420]

28. Friese CR, Earle CC, Silber JH, et al. Hospital characteristics, clinical severity, and outcomes for surgical oncology patients. Surgery. 2010; 147:602-609. [PubMed: 20403513]

29. Bilimoria KY, Bentrem DJ, Stewart AK, et al. Comparison of commission on cancer-approved and -nonapproved hospitals in the United States: implications for studies that use the National Cancer Data Base. J Clin Oncol. 2009; 27:4177-4181. [PubMed: 19636004]

30. Carroll JG. Continuous quality improvement and its implications for accreditation standards. Top Health Rec Manage. 1991; 11:27-37. [PubMed: 10110011]

31. Dimick JB, Cowan JA Jr, Colletti LM, et al. Hospital teaching status and outcomes of complex surgical procedures in the United States. Arch Surg. 2004; 139:137-141. [PubMed: 14769569]

32. White RH, Sadeghi B, Tancredi DJ, et al. How valid is the ICD-9-CM based AHRQ patient safety indicator for postoperative venous thromboembolism? Med Care. 2009; 47:1237-1243. [PubMed: 19786907]

33. Henderson KE, Recktenwald A, Reichley RM, et al. Clinical validation of the AHRQ postoperative venous thromboembolism patient safety indicator. Jt Comm J Qual Patient Saf. 2009; 35:370-376. [PubMed: 19634805]

34. Romano PS, Mull HJ, Rivard PE, et al. Validity of selected AHRQ patient safety indicators based on VA National Surgical Quality Improvement Program data. Health Serv Res. 2009; 44:182-204. [PubMed: 18823449]

35. Altom LK, Deierhoi RJ, Grams J, et al. Association between Surgical Care Improvement Program venous thromboembolism measures and postoperative events. Am J Surg. 2012; 204:591-597. [PubMed: 22906249]

36. Vartak S, Ward MM, Vaughn TE. Do postoperative complications vary by hospital teaching status? Med Care. 2008; 46:25-32. [PubMed: 18162852]

37. Rivard PE, Elixhauser A, Christiansen CL, et al. Testing the association between patient safety indicators and hospital structural characteristics in VA and nonfederal hospitals. Med Care Res Rev. 2010; 67:321-341. [PubMed: 19880671] 


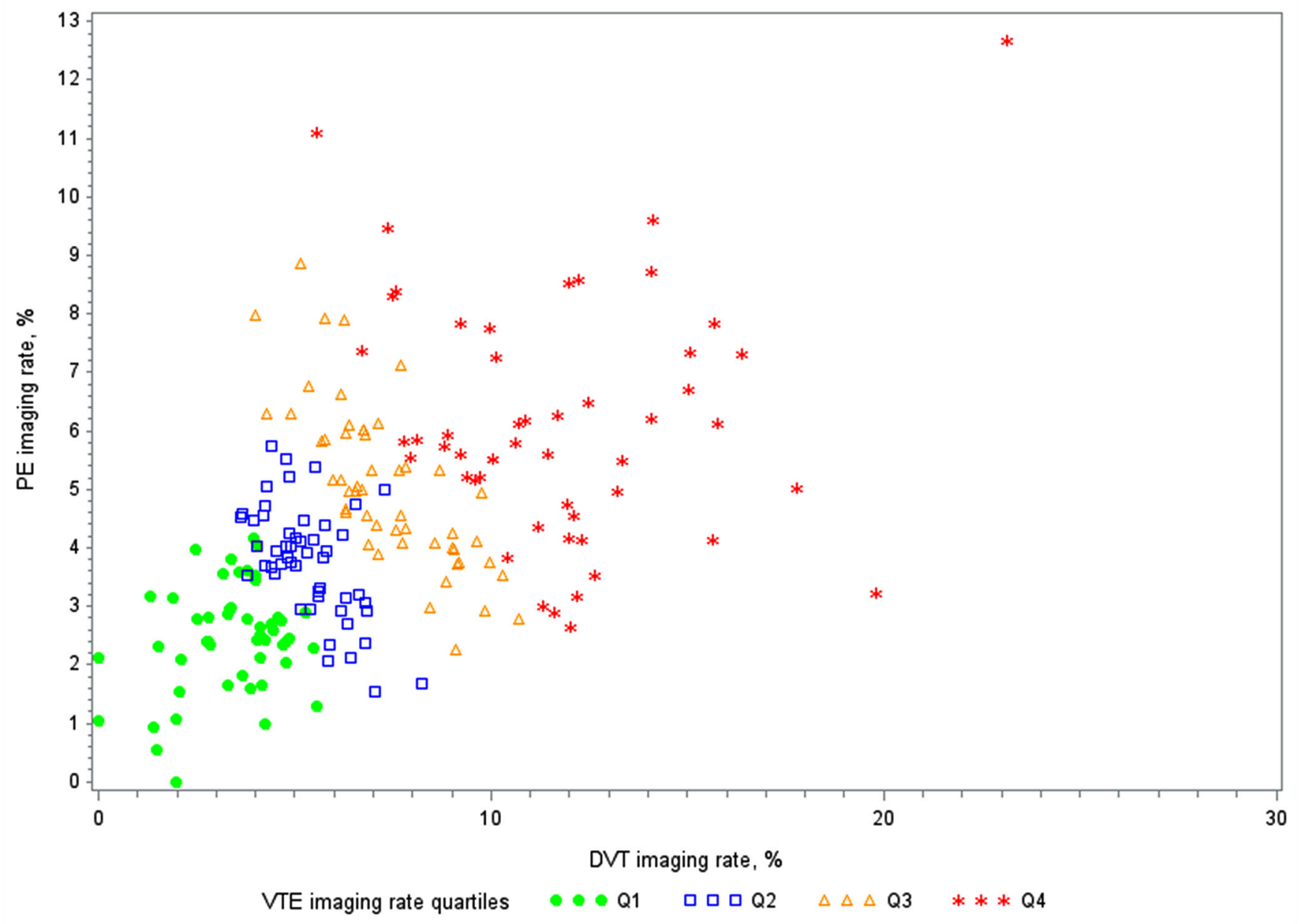

Figure 1.

Hospital deep vein thrombosis [DVT] and pulmonary embolism [PE] imaging rates.

Spearman's rho 52.1\% $(\mathrm{P}<0.001)$. 
(A) 30-days events

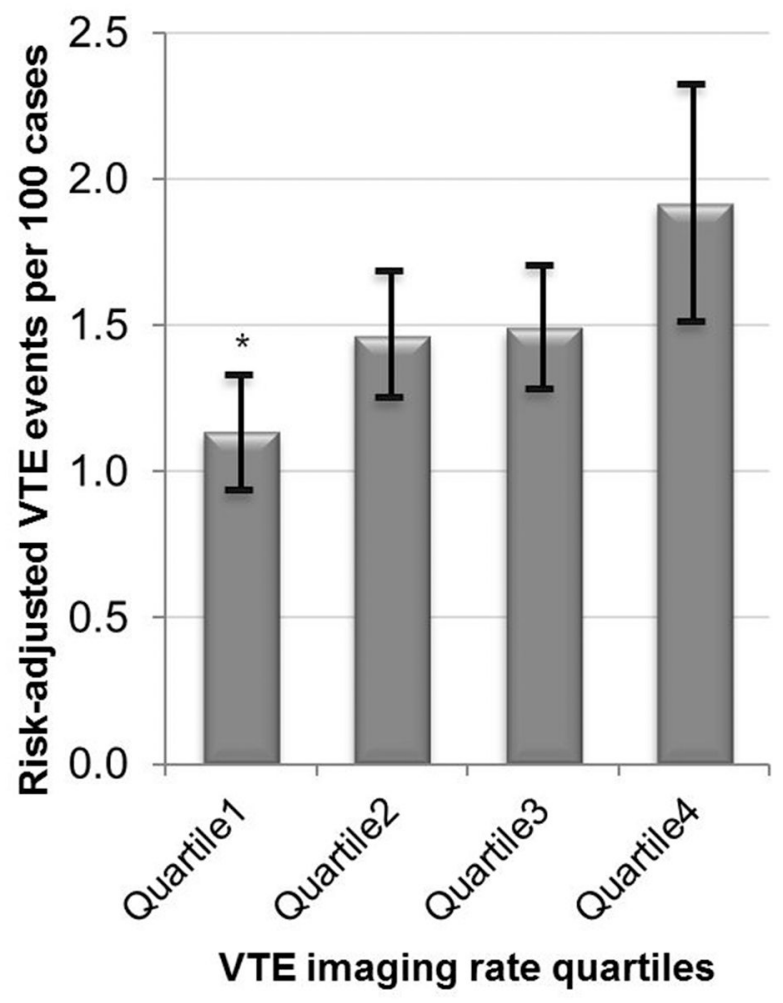

(B) Inpatient only events

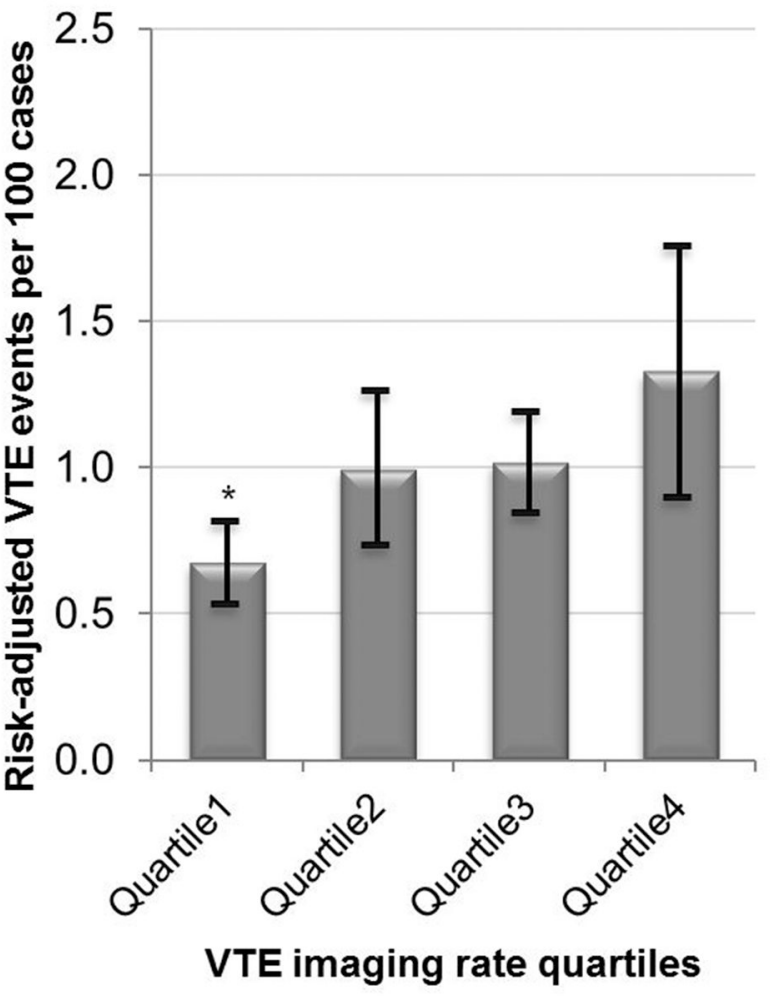

Figure 2.

Mean risk-adjusted venous thromboembolism [VTE] event rates by VTE imaging quartiles for VTE events captured at (A) 30-days and (B) while inpatient only.

$* \mathrm{P}<0.05$ two-tailed test for differences in mean compared to VTE imaging use rate quartile 4 (highest rate of VTE imaging). 
Table 1

Patient characteristics in ACS NSQIP (2009-2011) for 11 procedures.

\begin{tabular}{|c|c|c|}
\hline \multirow[t]{2}{*}{ Patient demographics } & $\mathbf{N}$ & $\%$ \\
\hline & 131512 & $100.0 \%$ \\
\hline \multicolumn{3}{|l|}{ Sex } \\
\hline Female & 75402 & $57.3 \%$ \\
\hline Male & 55718 & $42.4 \%$ \\
\hline Not available & 392 & $0.3 \%$ \\
\hline \multicolumn{3}{|l|}{ Age groups } \\
\hline$<50$ years & 40107 & $30.5 \%$ \\
\hline $50-64$ years & 43292 & $32.9 \%$ \\
\hline $65-79$ years & 35693 & $27.1 \%$ \\
\hline$>=80$ years & 12420 & $9.4 \%$ \\
\hline \multicolumn{3}{|l|}{ Race } \\
\hline White & 101837 & $77.4 \%$ \\
\hline Black & 13158 & $10.0 \%$ \\
\hline Hispanic & 5883 & $4.5 \%$ \\
\hline Asian & 1458 & $1.1 \%$ \\
\hline Others & 9176 & $7.0 \%$ \\
\hline \multicolumn{3}{|l|}{ BMI } \\
\hline Underweight $(<18.50)$ & 2960 & $2.3 \%$ \\
\hline Normal (18.50-24.99) & 27906 & $21.2 \%$ \\
\hline Overweight (25.00-29.99) & 32687 & $24.9 \%$ \\
\hline Class 1 obesity (30.00-34.99) & 21442 & $16.3 \%$ \\
\hline Class $2 \& 3$ obesity $(>=35.00)$ & 45368 & $34.5 \%$ \\
\hline Not available & 1149 & $0.9 \%$ \\
\hline
\end{tabular}

American Society of Anesthesiologists (ASA) physical Status classification

$\begin{array}{lrr}\text { I - no disturbance } & 2802 & 2.1 \% \\ \text { II - mild disturbance } & 51426 & 39.1 \% \\ \text { III - severe disturbance } & 65681 & 49.9 \% \\ \text { IV - life threating disturbance } & 10810 & 8.2 \% \\ \text { V - moribund } & 642 & 0.5 \% \\ \text { Not available } & 151 & 0.1 \%\end{array}$

Functional Status

$\begin{array}{lrr}\text { Independent } & 123106 & 93.6 \% \\ \text { Partial dependent } & 5864 & 4.5 \% \\ \text { Total dependent } & 2501 & 1.9 \% \\ \text { Not available } & 41 & 0.0 \%\end{array}$

Comorbidities and other preoperative characteristics

$20404 \quad 15.5 \%$

Chronic obstructive pulmonary disease (COPD) $\quad 7828 \quad 6.0 \%$

$\begin{array}{lll}\text { Congestive heart failure } & 1245 \quad 1.0 \%\end{array}$ 


\begin{tabular}{|c|c|c|}
\hline \multirow[t]{2}{*}{ Patient demographics } & $\mathbf{N}$ & $\%$ \\
\hline & 131512 & $100.0 \%$ \\
\hline Myocardial infarction and/or cardiac arrest & 15460 & $11.8 \%$ \\
\hline Neurologic events & 9804 & $7.5 \%$ \\
\hline SIRS / sepsis / septic shock & 9307 & $7.1 \%$ \\
\hline Disseminated cancer & 3263 & $2.5 \%$ \\
\hline Weight loss & 4735 & $3.6 \%$ \\
\hline Diabetic & 24738 & $18.8 \%$ \\
\hline Smoker & 24654 & $18.8 \%$ \\
\hline Steroid use & 5502 & $4.2 \%$ \\
\hline \multicolumn{3}{|l|}{ Abnormal preoperative laboratory values } \\
\hline Creatinine $>1.2$ & 15842 & $12.1 \%$ \\
\hline Albumin $<3.0$ & 9608 & $7.3 \%$ \\
\hline $\mathrm{HCT}<30$ & 8136 & $6.2 \%$ \\
\hline WBC $<4.5$ & 7930 & $6.0 \%$ \\
\hline $\mathrm{WBC}>10.0$ & 22182 & $16.9 \%$ \\
\hline Emergent case & 10598 & $8.1 \%$ \\
\hline \multicolumn{3}{|l|}{ Surgery type } \\
\hline Colon resection & 49460 & $37.6 \%$ \\
\hline Bariatric surgery & 31766 & $24.2 \%$ \\
\hline Rectal surgery & 11068 & $8.4 \%$ \\
\hline Total knee Reconstruction arthroplasty & 10837 & $8.2 \%$ \\
\hline Abdominal aortic aneurysm repair & 8320 & $6.3 \%$ \\
\hline Esophagectomy & 7969 & $6.1 \%$ \\
\hline Pancreatectomy & 6572 & $5.0 \%$ \\
\hline Coronary artery bypass graft (CABG) & 2461 & $1.9 \%$ \\
\hline Lung resection & 1585 & $1.2 \%$ \\
\hline Brain tumor resection & 1051 & $0.8 \%$ \\
\hline Cystectomy & 423 & $0.3 \%$ \\
\hline
\end{tabular}




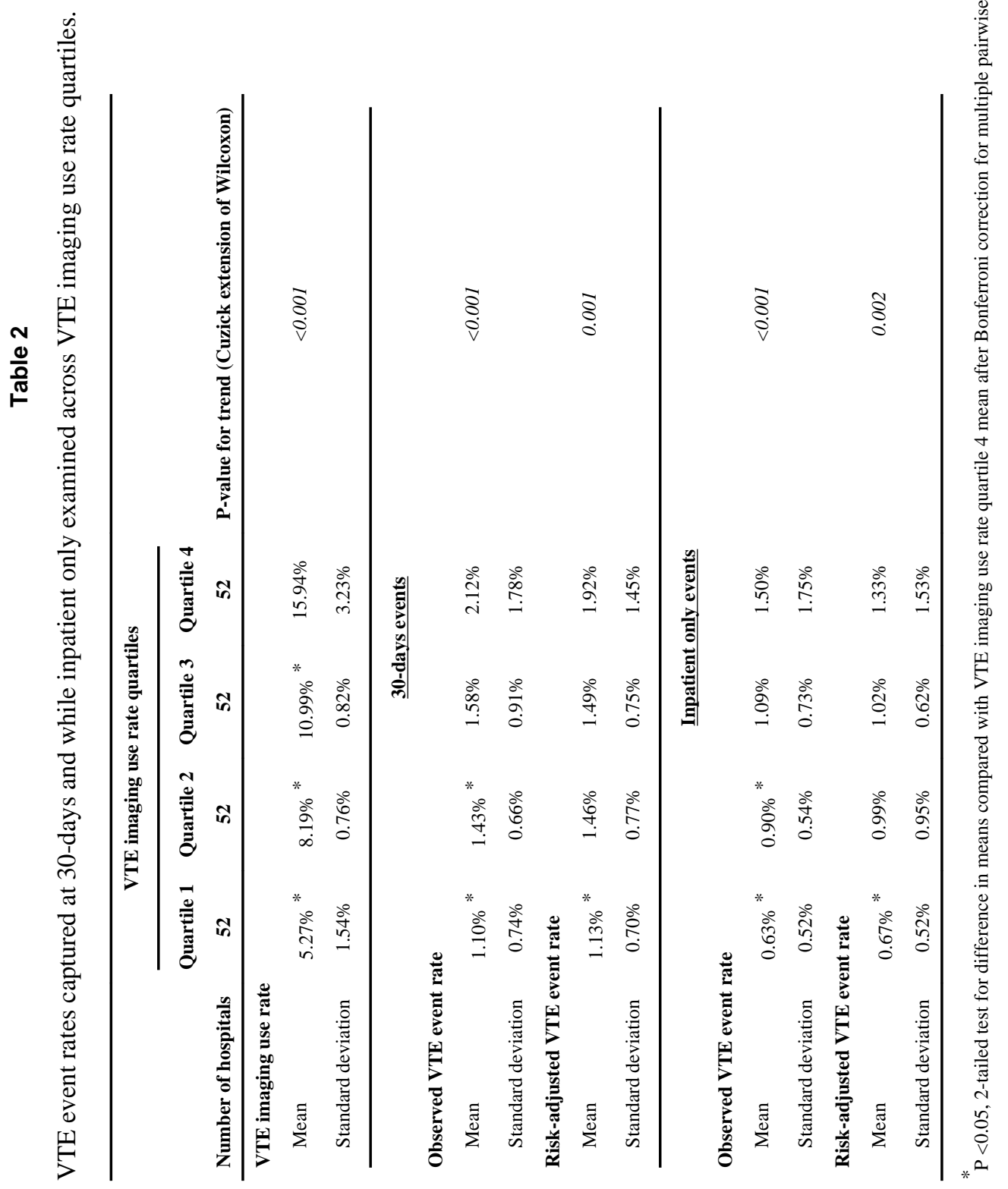


Table 3

Hospital characteristics.

\begin{tabular}{lrr}
\hline Hospital characteristics & $\mathbf{N}$ & $\mathbf{\%}$ \\
& $\mathbf{2 0 8}$ & $\mathbf{1 0 0 . 0 \%}$ \\
\hline Bed size & 114 & $54.8 \%$ \\
$\quad<500$ beds & 94 & $45.2 \%$ \\
$>=500$ beds & & \\
Teaching & 107 & $51.4 \%$ \\
Council of Teaching Hospitals and Health Systems (COTH) & 161 & $78.2 \%$ \\
Accreditation Council for Graduate Medical Education (ACGME) & 169 & $82.0 \%$ \\
American Medical Association (AMA) & 11 & $5.3 \%$ \\
American Osteopathic Association (AOA) & & \\
Structure quality characteristics & 189 & $91.8 \%$ \\
Joint Commission accreditation & 170 & $82.5 \%$ \\
ACS Commission on Cancer (CoC) accreditation & 85 & $41.3 \%$ \\
Level I Trauma certification & 44 & $21.4 \%$ \\
Burn Service & 107 & $51.9 \%$ \\
Transplant Service & &
\end{tabular}




\section{Table 4}

Multivariable linear regression of risk-adjusted rates showing the association between venous thromboembolism [VTE] imaging rate quartiles and risk-adjusted VTE event rate captured at 30-days and while inpatient only.

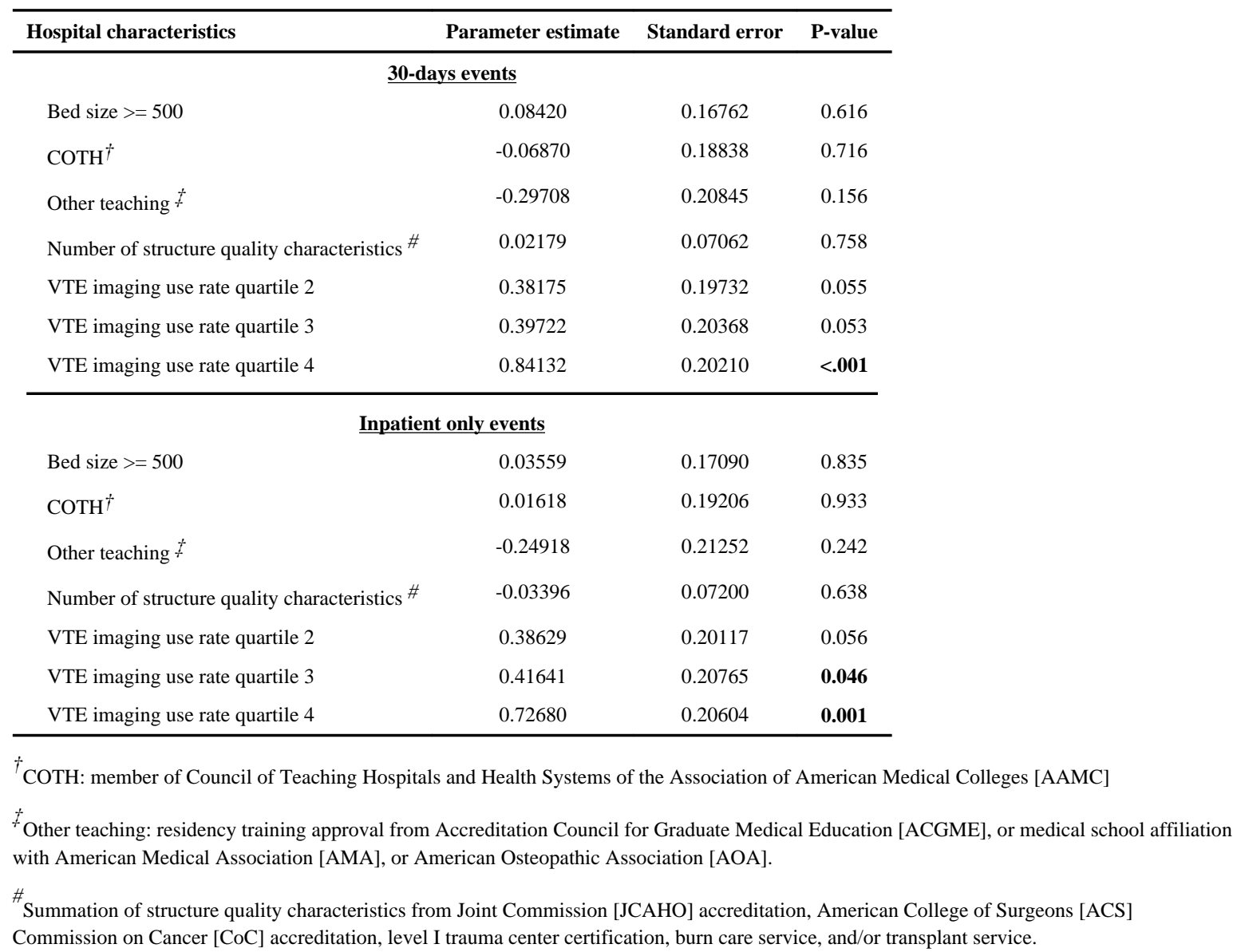

